\title{
Accumulation of deformation and acoustic emission in aluminum-magnesium alloy AMg6 in the conditions of deformation of the structural transition
}

\author{
S. V. Makarov, V. A. Plotnikov ${ }^{\dagger}$ \\ †plotnikov@phys.asu.ru
}

Altai State University, 61 Lenin Av., Barnaul, 656049, Russia

\begin{abstract}
In the course of thermomechanical loading of an aluminium-magnesium alloy under soft loading conditions, a monotonicstepwise or quasi-stepwise character of deformation accumulation has been observed. Monotonous accumulation of deformation is followed by a monotonous growth of the root-mean-square voltage of acoustic emission, as well as deformation jumps are followed by high-amplitude discrete signals of acoustic emission. The accumulation of deformation in an aluminum-magnesium alloy in a non-isothermic cycle is characterized by the two-stage process: low-temperature monotonous, with a low rate of deformation accumulation, and high-temperature stepwise or quasi-stepwise with a high-rate of deformation accumulation. The temperature transition point from the low-temperature area to the hightemperature area has the value of approximately $570^{\circ} \mathrm{C}$ and determines a low-to-high-rate transition of deformation accumulation. This kind of transition from the low-temperature area of deformation accumulation to the high-temperature one is characterized by a change in the mechanism of deformation accumulation and represents a deformation structural transition. Thus, the deformation structural transition is the transition from deformation accumulation that is controlled by thermally-activated dislocations climb to deformation accumulation that is controlled by grain boundary processes of perfect (lattice) dislocations generation at triple boundary junctions and occurs when mechanical stress, temperature and acoustic emission energy achieve certain critical values. While the mechanical stress grows, the transition temperature goes down and the acoustic emission oscillation energy rises thus showing that a certain balance of critical parameters is kept. The deformation structural transition is the result of the joint action of thermal fluctuations, static shifts of stress field and dynamic shifts of standing acoustic waves formed by primary signals of the acoustic emission at natural resonators of the sample volume under deformation.
\end{abstract}

Keywords: acoustic emission, intermittent flow, monotonic deformation, stepwise deformation, deformation of the structural transition.

\section{Накопление деформации и акустическая эмиссия в алюминиево-магниевом сплаве АМг-6 в условиях деформационного структурного перехода}

\author{
Макаров С. В., Плотников В.А. ${ }^{\dagger}$ \\ Алтайский государственный университет, пр. Ленина, 61, Барнаул, 656049, Россия
}

В ходе термомеханического нагружения алюминиево-магниевого сплава в условиях мягкой схемы нагружения наблюдается монотонно-скачкообразный или квазискачкообразный характер накопления деформации. Монотонное накопление деформации сопровождается монотонным ростом среднеквадратичного напряжения акустической эмиссии, деформационные скачки - высокоамплитудными дискретными сигналами акустической эмиссии. Накопление деформации в алюминиево-магниевом сплаве в неизотермичском цикле характеризуется двустадийным процессом: низкотемпературным монотонным, с низкой скоростью накопления деформации и высокотемпературным скачкообразным или квазискачкообразным, с высокой скоростью накопления деформации. Температурная точка перехода от низкотемпературной области к высокотемпературной области 
величиной около $570^{\circ} \mathrm{C}$ определяет переход от низкоскоростного накопления деформации к высокоскоростному. Переход от низкотемпературной области накопления деформации к высокотемпературной характеризуется сменой механизма накопления деформации и представляет собой деформационный структурный переход. Таким образом, деформационный структурный переход - переход от накопления деформации, контролируемой термически активируемым переползанием дислокаций, к накоплению деформации, контролируемой зернограничными процессами производства полных (решеточных) дислокаций на тройных зернограничных стыках и происходит при достижении механическим напряжением, температурой и энергией акустической эмиссии некоторых критических значений. По мере роста механического напряжения температура перехода снижается, а колебательная энергия акустической эмиссии возрастает, свидетельствуя тем самым о сохранения некоторого баланса критических параметров. Деформационный структурный переход есть результат совместного действия тепловых флуктуаций, статических смещений поля напряжений и динамических смещений поля стоячих акустических волн, сформированных первичными сигналами акустической эмиссии на естественных резонаторах деформируемого объема образца.

Ключевые слова: акустическая эмиссия, прерывистая текучесть, монотонная деформация, квазискачкообразная деформация, деформационный структурный переход.

\section{1. Введение}

Прерывистая текучесть есть характерный отклик алюминиево-магниевых сплавов на механическое нагружение, являющаяся следствием эффекта ПортевенаЛе Шателье $[1,2]$. Прерывистая текучесть связана с потерей устойчивости пластической деформации, проявляющаяся как релаксационный акт, свидетельствующий о повышении масштабного уровня накопления деформации [3]. На микроструктурном уровне прерывистая текучесть реализуется как процесс формирования деформационных полос, которые представляют собой области локализации пластической деформации [4]. При этом на зависимости напряжениедеформация в ходепрерывистой текучести формируются скачки (зубцы) напряжения, а деформационная полоса, ответственная за акты прерывистой текучести, является макроскопическим объектом и развивается из критического зародыша. Каждый акт прерывистой текучести связан с появлением одной полосы деформации [5].

Прерывистая текучесть сопровождается импульсами акустической эмиссии, коррелирующими с появлением полос деформации, то есть каждому скачку напряжений соответствует импульс акустической эмиссии [5]. Согласно публикации [6] проявление закономерностей прерывистой текучести и акустической эмиссии в алюминиево-магниевых сплавах есть следствие волновой природы деформации. Волна деформации, распространяясь от концентратора напряжений, стимулирует образование полос деформации и акустическую эмиссию.

Другим проявлением прерывистой текучести является прерывистая ползучесть (или эффект Савара-Массона $[7,8,9])$, наблюдающийся в тех же сплавах на кривых ползучести в виде последовательности скачков деформации величиной до 1 мкм [10]. Установлено, что даже при комнатной температуре прерывистая ползучесть развивается как спонтанная потеря механической устойчивости путем зарождения и распространения по поверхности образца полос макролокализации деформации, сопровождающейся формированием деформационного скачка величиной в несколько процентов. Структурно локализация деформации представляет собой последовательное зарождение и рост деформационных полос, которые последовательно заполняют всю поверхность деформируемого образца как процесс эстафетной передачи деформации от одной полосы к другой (последующей). Таким образом, деформационный скачок представляет собой пространственную и временную организацию деформационных полос, характеризующую пластическую неустойчивость нагруженного материала [6].

О пространственно-временной организации структуры из нескольких десятков деформационных полос свидетельствует и осциллирующий вид силового отклика системы машина-образец в ответ на скачкообразный прирост деформации нагруженного образца [11]. Рост одной полосы сопровождается одной силовой осцилляцией, продолжительностью 1-3 мс. Временной интервал между двумя соседними осцилляциями включает процессы упрочнения и разупрочнения, причем максимальное разупрочнение совпадает с максимумом скорости прироста деформации. Осциллирующий силовой отклик является отображением пространственно-временной структуры деформационных полос, спонтанное зарождение которых создает макроскопический скачкообразный прирост деформации [10,11].

Согласно некоторым представлениям природа пространственной и временной корреляции в ходе прерывистой текучести обусловлено наличием дальнодействующих долговременных напряжения изгиба в деформируемом материале [12], что обеспечивает каскадный механизм размножения деформационных полос [10].

В то же время при деформировании поликристаллов алюминия и других металлов и сплавов в мягкой схеме нагружения и в широком интервале температур наблюдается монотонный и скачкообразный характер накопления деформации, которые можно также трактовать как прерывистую ползучесть [13,14]. Эти особенности деформационного поведения металлов коррелируют с акустической эмиссией, сопровождающей процесс накопления деформации при высоких температурах: монотонное накопление деформации 
сопровождается низкоамплитудной акустической эмиссией; скачкообразное накопление деформации характеризуется высокоамплитудными единичными сигналами акустической эмиссии $[15,16,17]$.

Целью данной работы является проведение исследования деформации и акустической эмиссии в Al-Mg сплаве при нагружении в широком интервале температур вплоть до температуры плавления.

\section{2. Методика экспериментов}

Объектом исследований был выбран алюминиевомагниевый сплав АМг6. Согласно ГОСТ 4784-74 сплав АМг6 содержит магния в пределах 5.8-6.8\%, марганца $0.5-0.8 \%$, меди - менее $0.1 \%$, цинка - менее $0.2 \%$, железа и кремния - менее $0.4 \%$. Из пластины сплава АМгб вырезали образцы в виде стержней длиной 300 мм, в которых были сформированы области локализации деформации диаметром 4 мм и длиной 30 мм. Образцы предварительно отжигали при температуре $500^{\circ} \mathrm{C}$ в течение 1 часа и охлаждали с печью.

Механическое нагружение, измерение деформации, температуры и среднеквадратичного напряжения акустической эмиссии проводили с помощью установки, схематичное описание которой приведено в публикации [18]. Образец нагружали сдвиговым напряжением и измеряли сдвиговую деформацию. Нагруженный образец нагревали либо неизотермически от 25 и до $500^{\circ} \mathrm{C}$ либо изотермически, выбирая температуру в этом же интервале. Регистрация акустической эмиссии (среднеквадратичного напряжения) осуществлялась в селективном режиме на частоте около 100 кГц в полос частот 10 кГц, что обеспечивало низкий уровень шума, приведенного ко входу системы. Кроме среднеквадратичного напряжения акустической эмиссии $U$, в экспериментах анализировали и интегральный параметр акустической эмиссии $J=\Sigma U^{2} \Delta t_{i}$, где $\Delta t_{i}-$ шаг разбиения временного интервала процесса.

\section{3. Экспериментальные результаты}

На Рис. 1 представлены результаты изотермического нагружения образца из сплава АМг6 при температуpe $200^{\circ} \mathrm{C}$.

Как следует из приведенных на Рис. 1 данных в ходе роста нагрузки от нуля до 140 МПа можно выделить монотонную область накопления деформации и область, где наблюдается преимущественно скачкообразное накопление деформации. Монотонное накопление деформации сопровождается монотонным нарастанием среднеквадратичного напряжения акустической эмиссии, деформационные скачки сопровождаются высокоамплитудными дискретными сигналами акустической эмиссии, причем наблюдается корреляция между скачком деформации и высокоамплитудным акустическим импульсом. Вклад монотонного накопления мал и составляет около $2 \%$, в то время как прирост деформации величиной около $19 \%$ осуществлен за счет макроскопических деформационных скачков.
В то же время в неизотермическом цикле (Рис. 2) в ходе нагрева примерно до $520^{\circ} \mathrm{C}$ и в условиях действия нагрузки 120 МПа накопление деформации и акустическая эмиссия существенно другие.

Из приведенных на Рис. 2 данных следует, что при нагреве нагруженного образца наблюдается два участка накопление деформации (на Рис. 2 область 1 и область 2). В низкотемпературной области 1 в температурном интервале $20-400^{\circ} \mathrm{C}$ монотонному накоплению деформации величиной примерно $3 \%$ соответствует акустическая эмиссия, характеризуе-

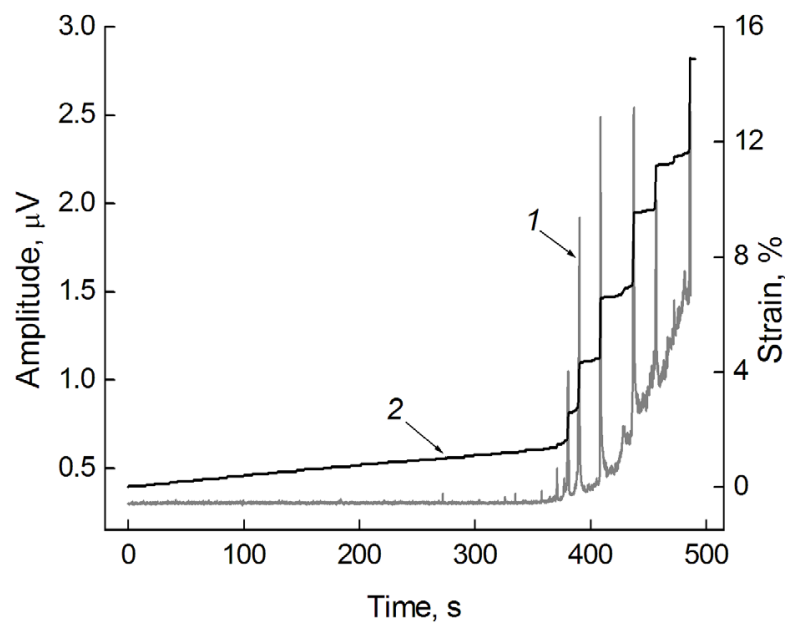

Рис. 1. Акустическая эмиссия (1) и накопление деформации (2) в цикле изотермического нагружения образца из сплава АМг6 возрастающей нагрузкой до $140 \mathrm{MПа,} \mathrm{скорость} \mathrm{нагружения}$ около $0.35 \mathrm{M \Pi а} / \mathrm{c}$.

Fig. 1. Acoustic emission (1) and strain accumulation (2) in the isothermal loading cycle of alloy AMg6 (1560) with increasing load up to $140 \mathrm{MPa}$, loading rate $-0.35 \mathrm{MPa} / \mathrm{s}$.

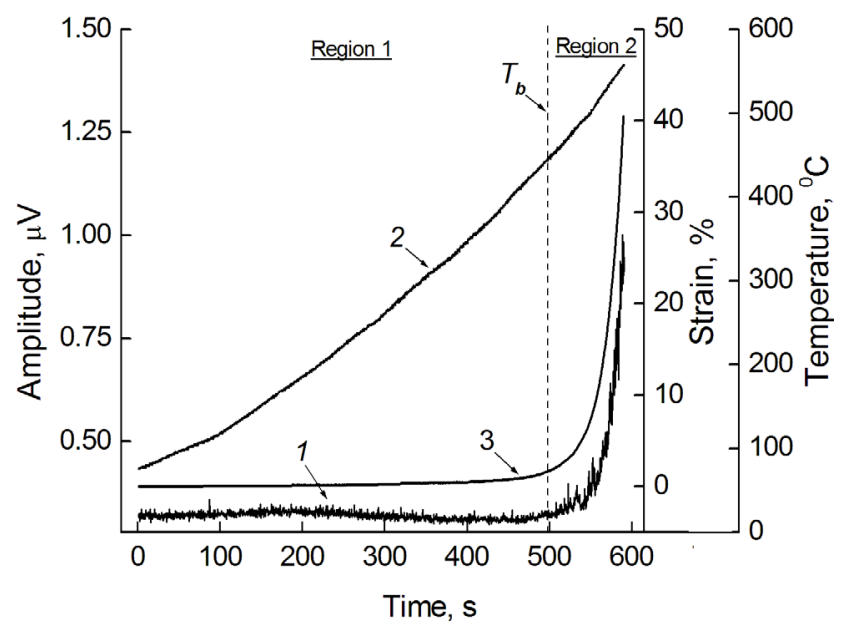

Рис. 2. Акустическая эмиссии (1), температура (2), накопление деформации (3) при нагреве образца АМг6 в условиях действия постоянной нагрузки 120 МПа. Скорость нагрева около 1 град/с. Пунктирная линия делит весь процесс накопления деформации на две области: в области 1 скорость накопления мала; в области 2 скорость накопления существенно выше.

Fig. 2. Acoustic emission (1), temperature (2), the accumulation of deformation (3) during heating of a sample of AMg6 (1560) under the action of a constant load of $120 \mathrm{MPa}$. Heating rate $-1 \mathrm{deg} / \mathrm{s}$. Region 1 - low strain accumulation rate, region $2-$ high strain accumulation rate. 
мая монотонным нарастанием среднеквадратического напряжения акустической эмиссии при нагреве. В высокотемпературной области 2 при температуре около $400^{\circ} \mathrm{C}\left(T_{2 p}\right)$ характер накопления деформации и акустической эмиссии меняется: быстрому накоплению деформации соответствует активный рост амплитуды среднеквадратичного напряжения акустической эмиссии. Это может свидетельствовать, что в области 2 после $400^{\circ} \mathrm{C}$ активизируется новый механизм накопления деформации, который становится основным. Этот механизм можно трактовать как квазискачкообразный (деформационные скачки в эксперименте не разрешаются), обеспечивающий основной вклад в накопление деформации (в данном случае до $37 \%)$.

\section{4. Анализ экспериментальных результатов}

Для определения граничной температуры перехода от области 1 к области 2 в каждом термомеханическом цикле проанализируем накопление деформации с помощью сложной экспоненциальной функции [19]

$$
\varepsilon=\varepsilon_{0}+\varepsilon_{01} \exp \left(v_{1} t\right)+\varepsilon_{02} \exp \left(v_{2} t\right) .
$$

Здесь параметры $\varepsilon_{0}, \varepsilon_{01}, \varepsilon_{02}-$ деформационные константы, а параметры $v_{1}$ и $v_{2}$ - скорости накопления деформации в области 1 и области 2 соответственно. Точка пересечения экспонент позволяет определить момент времени и граничную температуру перехода. Данные такого анализа зависимости деформации от времени в неизотермических циклах в интервале механических нагрузках 40-200 МПа приведены на Рис. 3, а на Рис. 4 приведены данные по зависимости величины колебательной энергии акустической эмиссии, регистрируемой в ходе накопления деформации в области 2, от величины механического напряжения в цикле.

Температурная точка перехода от низкотемпературной области 1 к высокотемпературной области 2 величиной около $420^{\circ} \mathrm{C}$ на Рис. 3 определяет переход от низкоскоростного накопления деформации квысокоскоростному. Скорость накопления деформации в первом температурном интервале (в области 1) почти в четыре раза меньше скорости накопления в области 2. Однако такой переход возможен лишь при механическом напряжении не ниже 90 МПа. Кроме того (Рис. 4) по мере роста механического напряжения происходит существенный рост колебательной энергии акустической эмиссии в ходе деформирования образца в области 2 и при напряжении $90 \mathrm{MПа} \mathrm{достигает}$ величины около $30 \cdot 10^{-12} \mathrm{~B}^{2} \mathrm{c}$. Совокупности этих данных позволяет трактовать переход из области 1 в область 2 как деформационный структурный переход, а указанные выше значения температуры, механического напряжения и колебательной энергии акустической эмиссии как критические параметры такого перехода. То есть деформационный структурный переход в ходе термомеханического нагружения материала есть результат совместного действия тепловых флуктуаций, статических смещений поля напряжений и динамических смещений поля стоячих акустических волн, сформированных первичными сигналами акустической эмиссии на естественных резонаторах деформируемого объема образца [19].

На микроструктурном уровне деформационный структурный переход представляет собой переход от накопления деформации, контролируемой термически активируемым переползанием дислокаций $[20,21]$, к накоплению деформации, контролируемой зернограничными процессами проскальзывания [22] и производства полных (решеточных) дислокаций на тройных зернограничных стыках [23] и происходит при достижении механическим напряжением, температурой и энергией акустической эмиссии некоторых критических значений. Было подчеркнуто, что для компенсации пластических неувязок в ходе

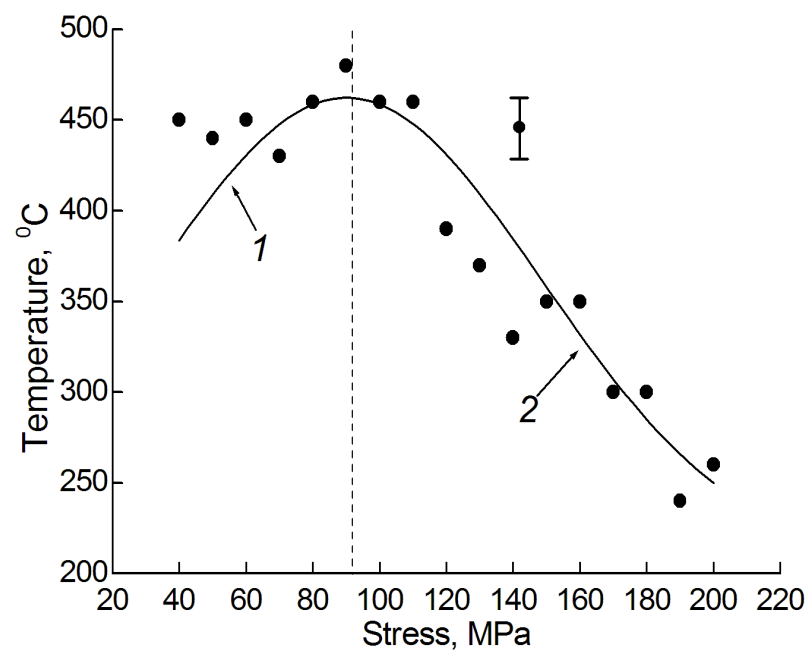

Рис. 3. Зависимость граничной температуры перехода из области 1 в область 2 от механического напряжения в циклах термомеханического нагружения.

Fig. 3. Dependence of the boundary temperature of the transition from region 1 to region 2 on the mechanical stress in the cycles of thermomechanical loading.

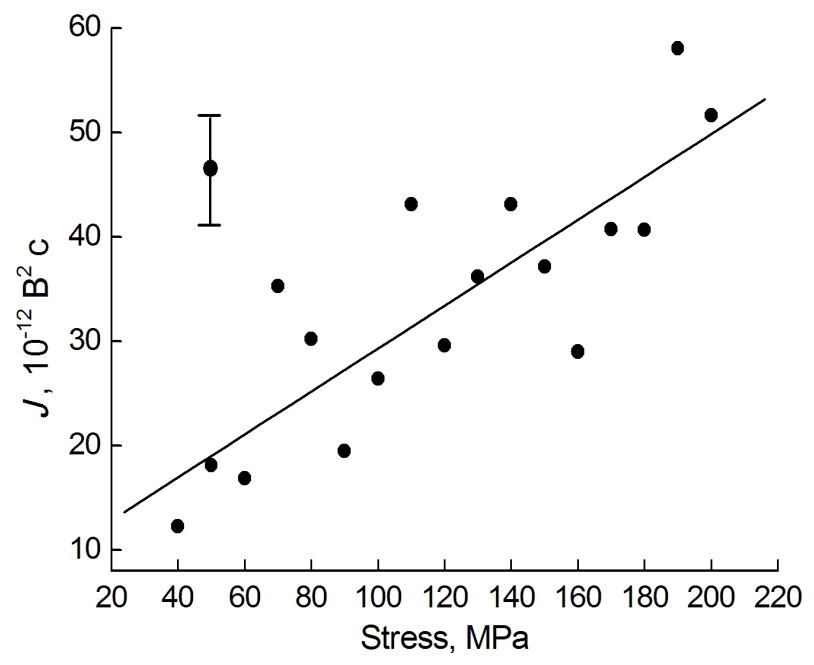

Рис. 4. Зависимость энергии акустической эмиссии, продуцируемой в области 2 , от механического напряжения.

Fig. 4. The dependence of the energy of acoustic emission produced in region 2 on the mechanical stress. 
зернограничного проскальзывания необходима генерация решеточных дислокаций, плотность которых должна достигать $10^{8} \mathrm{~cm}^{-2}$ [22]. Действительно, скольжение решеточных дислокаций в приграничной области считается доминирующим механизмом сверхпластической деформации $[24,25]$. Экспериментальным подтверждением генерации решеточных дислокаций в ходе зернограничного проскальзывания является система деформационных полос, формируемая при деформировании алюминия в области $2[15,26]$. По мере роста механического напряжения температура перехода снижается, а колебательная энергия акустической эмиссии возрастает, свидетельствуя тем самым о сохранении некоторого баланса критических параметров.

Макроскопическим проявлением деформационного структурного перехода является величина накапливаемой деформации и, главное, скорости накопления деформации в разныхструктурныхсостояниях. Скорость накопления деформации после деформационного структурного перехода в четыре, пять раз превосходи скорость накопления в низкотемпературной области. На основании такого подхода накопление деформации в высокотемпературной области можно определить как квазискачкообразное.

Колебательная энергия акустической эмиссии (как отмечено выше) должна накапливаться в объеме деформируемого образца. Единственным процессом, который может обеспечить накопление колебательной энергии, является процесс формирования стоячих акустических волн на естественных резонаторах в системе образец-волновод [27]. Разумеется, бегущая волна (точнее волновой пакет) также характеризуется некоторой колебательной энергией, однако эта энергия быстро затухает при распространении волнового пакета. При формировании стоячей волны энергия первичных сигналов акустической эмиссии перераспределяется по всем резонаторам системы, однако отметим, что для нас важен резонатор в области локализации деформации. Именно колебательная энергия стоячей волны этого резонатора совместно со статическими смещениями и тепловыми флуктуациями обеспечивает активацию элементарных сдвигов и их корреляцию в области локализации деформации. Рост энергии акустической эмиссии при переходе в область 2 может свидетельствовать о повышении корреляционных эффектов в системе элементарных деформационных актов [14]. Фактически процесс накопления деформации в области 2 контролируется акустической эмиссией (точнее акустическими стоячими волнами), в то время как в области 1 эта корреляция отсутствует.

\section{5. Заключение}

Деформационный структурный переход является переходом от накопления деформации, контролируемой термически активируемым переползанием дислокаций, к накоплению деформации, контролируемой зернограничным процессом производства полных решеточных дислокаций на тройных зернограничных стыках.
Для реализации деформационного структурного перехода температура, механическое напряжение и колебательная энергия акустического поля стоячих волн, сформированное первичными сигналами акустической эмиссии должны достигать критических значений: температура должна быть в интервале $470-250^{\circ} \mathrm{C}$, механическое напряжение - в интервале 90-200 МПа, колебательная энергия стоячих волн акустической эмиссии - не ниже $30 \cdot 10^{-12} \mathrm{~B}^{2}$ c. Причем чем выше механическое напряжение, тем ниже критическая температура.

Макроскопически деформационный структурный переход представляет собой переход от монотонного накопления деформации к скачкообразному или квазискачкообразному и является результатом совместного действия тепловых флуктуаций, статических смещений и динамических колебательных смещений стоячих звуковых волн, сформированных на естественных резонаторах в области локализации деформации образца.

Скачкообразное (или квазискачкообразное) накопление деформации в высокотемпературной области сопровождается высокоамплитудной акустической эмиссией, что приводит к формированию глобального макроскачка. Такой характер деформации свидетельствуют о высокой корреляции элементарных деформационных актов, где акустическая эмиссия выступает как фактор корреляции, а макроскопический масштаб корреляции определяет длина акустической стоячей волны.

\section{Литература/References}

1. A. Portevin, F. Le Chatelier. Seances Acad. Sci. 176, 507 (1923).

2. P. Hahner, A. Ziegenbein, E. Rizzi, H. Neuhauser. Phys. Rev. B. 65 (13), 134109 (2002). Crossref

3. M. M. Krishtal. Physical Mesomechanics. 7, 5 (2004)

4. M. M. Krishtal. Phys. Metals Metallogr. 75, 480 (1993).

5. M. M. Krishtal, D. L. Merson. Phys. Metals Metallogr. 81, 104 (1996).

6. M. M. Krishtal, D. L. Merson. Phys. Metals Metallogr. 71, 187 (1991).

7. A.P. Masson. Annals of Chemistry and Physics. 3, 451 (1841).

8. A.A. Shibkov, R. Yu. Koltsov, M.A. Zheltov, A.V. Shuklinov, M.A. Lebedkin. Bulletin of the Russian Academy of Sciences: Physics. 70, 1570 (2006).

9. A. A. Shibkov, A. E. Zolotov, M. A. Zheltov, A. A. Denisov. Crystallography Reports. 57, 105 (2012). Crossref

10. A. A. Shibkov, A. E. Zolotov, M. F. Zheltov, et al. Technical Physics. The Russian Journal of Applied Physics. 59, 508 (2014). Crossref

11. A. A. Shibkov, A.E. Zolotov, M.F. Zheltov, et al. Phys. Solid State. 56, 881 (2014). Crossref

12. A. A. Shibkov, A.E. Zolotov, M.F. Zheltov, et al. Phys. Solid State. 56, 889 (2014). Crossref

13. V.A. Plotnikov, S. V. Makarov. Technical Physics Letters. 34, 255 (2008). Crossref 
14. S. V. Makarov, V. A. Plotnikov, A. I. Potekaev. Russ. Phys. J. 56, 630 (2013). Crossref

15. V. A. Plotnikov, S. V. Makarov. Phys. Met. Metallogr. 105, 395 (2008). Crossref

16. V. A. Plotnikov, S. V. Makarov. Phys. Met. Metallogr. 106, 202 (2008). Crossref

17. M.A. Krishtal, D.L. Merson, A.V. Katsman, M. A. Vyboishchik. Phys. Met. Metallogr. 66, 169 (1988).

18. S. V. Makarov, V.A. Plotnikov. Deformation and destruction of materials. 10, 21 (2015). (in Russian) [C.В. Макаров, В.А. Плотников. Деформация и разрушение материалов. 10, 21 (2015).]

19. S. V. Makarov, V. A. Plotnikov, M. V. Lysikov. Fundamental problems of modern materials science. 3, 309 (2016). (in Russian) [C.B. Макаров, В.А. Плотников, M.B. Лысиков. Фундаментальные проблемы современного материаловедения. 3, 309 (2016).]

20. M.M. Myshlyaev. Polzuchest' poligonizovannykh struktur. In: Nesovershenstva kristallicheskogo stroyeniya i martensitnyye prevrashcheniya. Moscow, Nauka (1972) pp. 194-234. (in Russian) [M.М. Мышляев. Ползучесть полигонизованных структур. Сб.
Несовершенства кристаллического строения и мартенситные превращения. Москва, Наука (1972) c. $194-234$.]

21. V.M. Rozenberg. Polzuchest' metallov. Moscow, Metallurgiya (1967) 276 p. (in Russian) [В. М. Розенберг. Ползучесть металлов. Москва, Металлургия (1967) 276 c.]

22. O.A. Kaibyshev, R.Z. Valiev. Granitsy zeren i svoystva metallov. Moscow, Metallurgiya (1987) 214 p. (in Russian) [O. А. Кайбышев, Р. З. Валиев. Границы зерен и свойства металлов. Москва, Металлургия (1987) 214 c.]

23. M. Yu. Gutkin, I. A. Ovidko, N. V. Skiba. Phys. Solid State. 47, 1662 (2005). Crossref

24. K. A. Padmanabhan, H. Gleiter. Mater. Sci. Eng. A381, (12), 28 (2004). Crossref

25. A.K. Mukherjee. Mater. Sci. Eng. A322 (1-2), 1 (2002). Crossref

26. B. Baudelet, M. Suery, A. Eberhardt. J. Phys. 36, 281 (1975).

27. S. V. Makarov, V. A. Plotnikov, A. I. Potekaev. Russ. Phys. J. 57, 950 (2014). Crossref 